Barbara J. Panessa-Warren

Allied Health Resources Dept., SUNY, Stony Brook, NY 11794

George T. Tortora

Medical Technology/C1inical Microbiology Dept., SUNY, Stony Brook, NY 11794

\title{
FEB 121988
}

John B. Warren

Instrumentation Division, Brookhaven National Laboratory, Upton, NY 11973

When deprived of nutrients, spore forming bacilli produce endospores which are remarkably resistant to chemical sterilization. 1,2 Little is known about the morphology and response of these spores following exposure to sporocidal agents. Light microscopy does not provide sufficient resolution for studying the rupture of the spore coat and fate of intracellular material. Transmission and scanning electron microscopy offer superior resolution but require specimen preparation methods that induce physiologic as well as morphologic changes in the spores, thereby making accurate interpretation of micrographs difficult. To eliminate the possible artifacts induced by chemical fixation, dehydration, embeddment, staining and sectioning, treated and non-sporocidetreated endospores of B. thuringiensis and B. subtilis were imaged by $x$-ray contact microscopy using monochromatic $x$-rays.

Soft $x$-rays (1-10 nm wavelength) offer the biologist distinct advantages for lmaging samples that are particularly sensitive to electron or proton beams, or to conventional specimen preparation procedures. ${ }^{3}$ These $x$-rays produce less specimen damage than electrons and protons, and they penetrate the blological specimen more easily than electrons without necessitation of a vacuum environment. ${ }^{4}$ By using monochromatic $x$-rays for exposure, it is possible to augment selective absorptivity and produce $x-r$ ay contact replicas that reveal the location of specific elements within the tissue. 5 With the advances in synchrotron technology, it is now possible to obtain monochromatic $x$-rays with suffictent coherence, brightness and dose for the brief exposure times required with blological hydrated samples. Although quantitative $x$-ray microanalysis of frozen biological tissue can also identify specific elements within the sample, soft $x$-ray absorption edge microscopy offers a less damaging method that requires 1ittle specimen preparation or skil1; has an inherent contrast mechanism (selective $x$-ray absorptivity) which eliminates the need for staining or chemically fixing a specimen; ${ }^{3}$ and the ability to image elements (such as oxygen, nitrogen, carbon, etc.) that cannot readily be viewed or identified by conventional x-ray microanalysis methods. This paper represents some of our first attempts at absorption edge imaging and in no way presents this methodology as a quantitative trace analysis technique.

\section{METHODS}

\subsection{Endospore Preparation}

Bacilius subtilis var niger ATCC 7932 was obtained from American Type Culture collection and Bacillus thuringiensis was obtained from Dipel, Abbot Laboratories. Spores were grown on slants of AK Sporulating Agar No. 2 (BBL, Cockeysville, MD) in 16 oz prescription bottles at $35^{\circ} \mathrm{C}$ aerobically. After maximal sporulation, the spores were harvested in delonized water and heated 
to $80^{\circ} \mathrm{C}$ for $20 \mathrm{~min}$ to $\mathrm{kill}$ any remaining vegetative cells. The spores were washed three limes with sterlle delonlyed water and stock suspenstons were stored at $2-8^{\circ} \mathrm{C}$ unt 11 needed. For comparison, spore samples were either vacuum dried onto aluminum scanning mounts or fixed in $1.5 \%$ glutaraldehyde in $0.1 M$ cacodylate buffer, followed by acetone dehydration and critical point drying in liquid $\mathrm{CO}_{2}$. These samples were rotary coated with 7-10 nm of goldpalladium in an Edwards vacuum evaporator prior to examination in an AMRAY $1000 \mathrm{~A} \mathrm{SEM} \mathrm{at} 20$ or $30 \mathrm{keV}$ accelerating voltage. Spores treated with a vanadium-contalning sporocide for $30 \mathrm{sec}, 10 \mathrm{~min}$ and $50 \mathrm{~min}$ were elther vacuum drled or prepared in the aforementioned way and vlewed by scanning electron microscopy.

\section{$1.2 \mathrm{X}$-ray Detector and Exposures}

Polymethyl methacrylate (PMMA) dissolved in chlorobenzene was spun at I $\mu \mathrm{m}$ thickness onto sillcon wafers and baked for $1 \mathrm{hr}$ at $156^{\circ} \mathrm{C}$. B. thuringiensis and $B$. subtilis spores were smeared as a monolayer onto the photoresist and excess fluid wicked-off with filter paper. These spores were exposed to monochromatic $x$-rays near the nitrogen absorption edge $(30.99 \mathrm{~nm} \lambda)$ and above and below the V LIII absorption edge. B. thuringiensis and B. subtilis spore preparations treated with sporocide for $30 \mathrm{sec}, 10 \mathrm{~min}$ and $50-80$ min were exposed to monochromatic $x$-rays near the nitrogen edge and above and below the $V$ LIII edge. For this study the exposures were made at a dedicated soft $x$-ray beamline (U15) at the high brightness synchrotron radiation facility at Brookhaven National Laboratory, National Synchrotron Light Source. A toroidal grating monochromator provided a monochromatic beam at the $750 \mathrm{MeV}$ VUV storage ring. A11 of the $x$-ray exposures ranged from 20.7 to 28.3 iA minutes.

Following $x$-ray exposure, the spores were washed off the photoresist and the photoresist developed in $1: 1$ isopropanol/methy1-isobutyl ketone (MIBK). The x-ray contact replicas were rotary coated with 5-8 nm gold-palladium in an Edwards vacuum evaporator and viewed at. $60-75^{\circ}$ tilt, 20 or $30 \mathrm{keV}$ accelerating volt age.

\section{RESULTS AND DISCUSSION}

$X$-ray contact replicas of $B$. subtilis and $B$. thuringiensis endospores made following exposure to $x$-rays near the nitrogen edge revealed detalls of the spore coat and exosporfum. Nitrogen absorption maps of the spores were used to monitor spore morphology and general protein distribution on the silicon wafer. At $30 \mathrm{sec}$ after sporocide treatment, nitrogen $x$-ray maps of $B$. thuringlensis revealed alterations in the spore coat and at $5 \mathrm{~min}$ post-treatment complete disruption of the spore coat. B. subtilis treated with sporocide for 1-5 min produced nitrogen $x$-ray maps with wrinkling and blebs on the spore coat but complete disruption of the spore coat was not found even after $80 \mathrm{~min}$ of sporocide treatment.

$X$-ray exposures of sporocide-treated B. subtilis spores made below the absorption edge of vanadium (V) produced $x$-ray contact replicas with no clearly intact spores. The outline of the disrupted spore coat could be seen surrounded by a puddle of material with numerous globular inclusions (Fig. 1 ). Areas of the photoresist lacking the hazy images of the spores also lacked the puddles of globular material, suggesting that the sporocide treated B. subti11s spores may exude or lose their intracellular contents without the total destruction of the spore coat. Above the absorption edge of $V$ the same sporoclde-treated B. subtilis spores revealed the hazy image of the spore coat and 
a surrounding puddle of materlal, however, in this case the formerly globular inclustons in the puddle now appear dendritic with six or more arms radiating from a central core ( $F i g .2)$ ). These roselte-like arrays surrounding the spore coats were only seen in exposures made just above the V L III absorption edge. The nitrogen $x$-ray replicas and replicas made below the $V$ LIII edge using the same specimen showed no rosettes but rather indistinct globular material in the puddles surrounding the spore coats. One would expect areas of the specimen originally containing $V$ to be strongly imaged when exposed to monochromatic $x$-rays just above the absorption edge of the $V L_{I I I}$ line and these same structures to be poorly imaged at $x$-ray wavelengths below the absorption edge of the element in question.

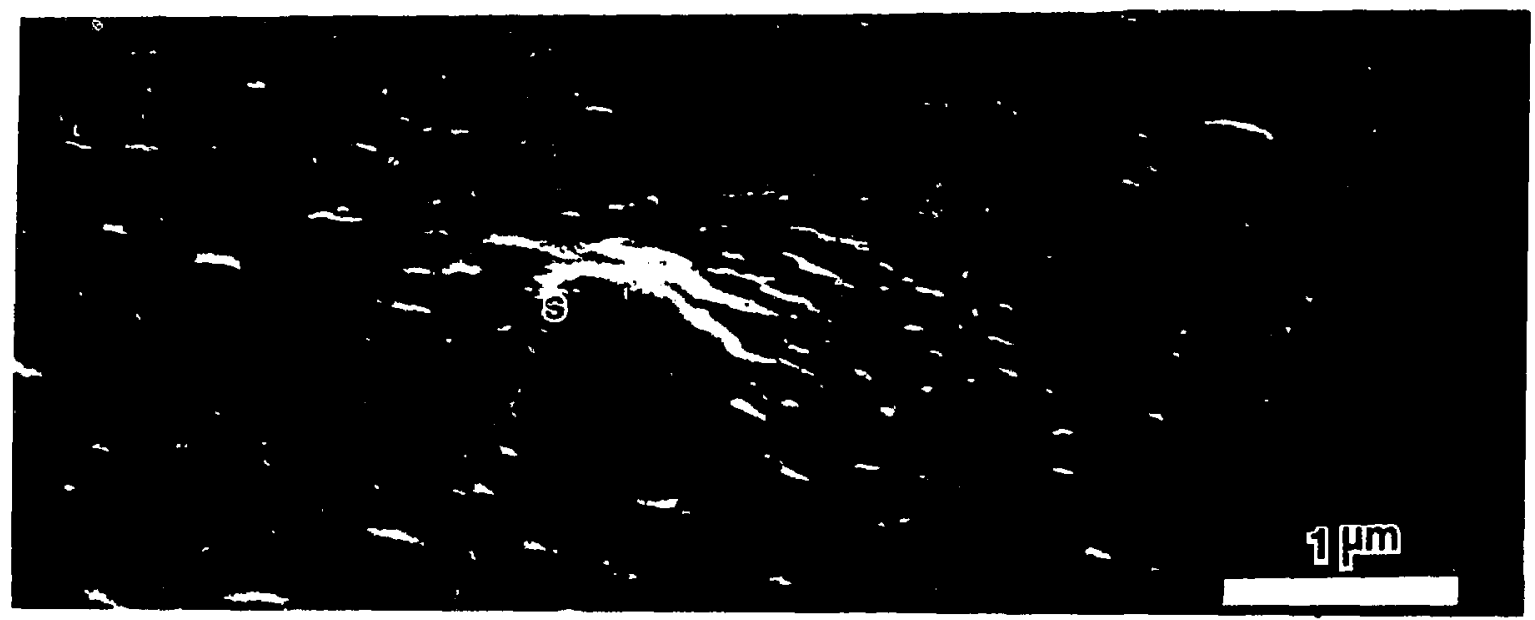

Fig. 1. Sporocide treated B. subtilis $x$-ray contact replica taken below the absorption edge of vanadium shows hazy image of spore coat (s) surrounded by a region of material with elliptical inclusions.

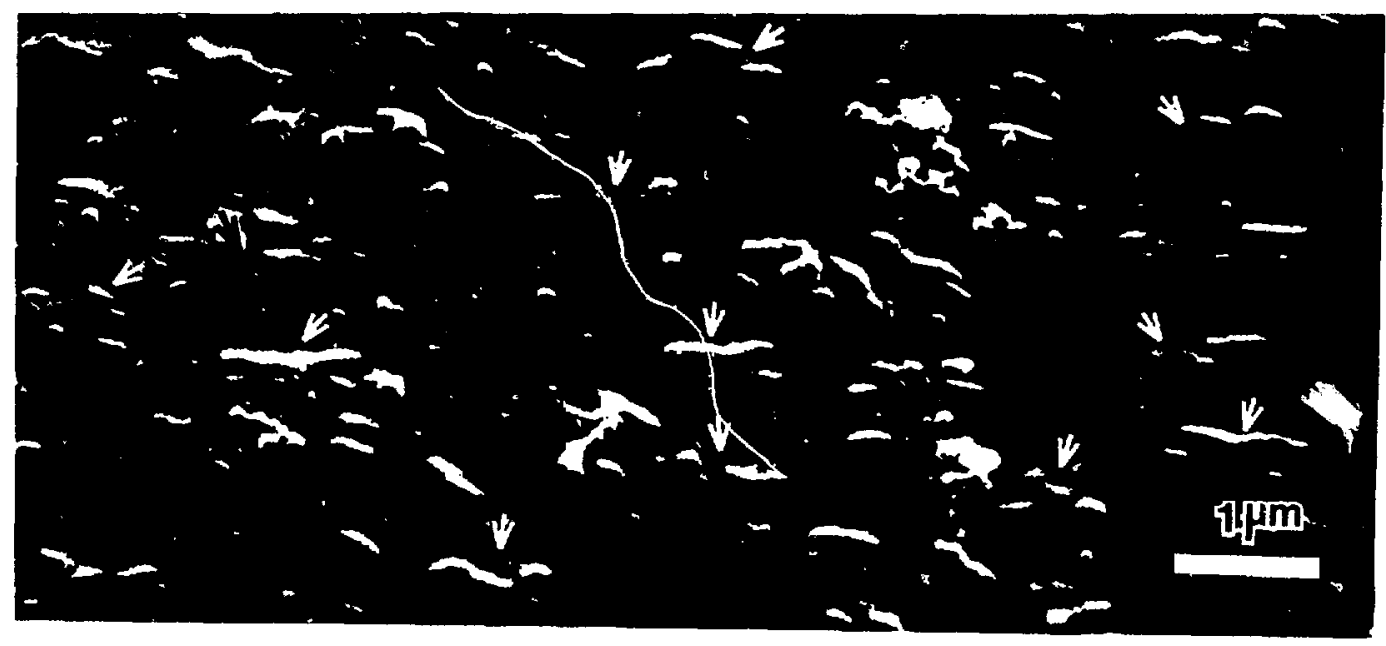

F1g. 2. Same sample as figure 1 when Imaged with $x$-rays above the absorption edge of vanadium shows same puddle surrounding the spore coat, but the inclusions appear crystalline or as rosettes (arrows). 
$X$-ray contact replicas of sporoctde treated B. Lhuringiensis spores revealed such extensive fragmentat ton of tho spore coat and cellular debris at 30 sec or more post-sporocide treatment that it was not possible to identify individual structures in the micrographs. This was also the case with the B. thuringiensis glutaraldehyde fixed and vacuum dried control preparations.

The capability to reveal compositional information from the same specimen by imaging it with different monochromatic x-rays poses many exciting possibilities. The fact that the rosette-like images seen above the $V$ absorption edge may represent the $V$ in the sporocide (bound to endogenous dipicolinic acid) suggests that it may be possible to learn how these sporocides may attack and kill the more resistant bacterial spores. Although it might be considered that this type of analysis could be done by electron or $x$-ray induced $x$-ray microanalysis, it is not possible to produce images of, or analyze these puddles around the disrupted spores following most specimen preparation procedures. By $x$-ray fluorescence spectrometry it would be 1mpossible to obtain this spatial resolution, and by electron microprobe analysis the problems of mass loss, and orientation of an unstafned sample, would make this type of analysis extremely difficult. The ability to image partially hydrated, unstained unfixed biological material and gain immediate information about the possible localization of a specific element without the beam damage and specimen trauma experienced with other analytical techniques, is an exciting step forward in the realm of biological analysis.

\section{ACRONOTLEDGIENT}

The authors are deeply indebted to Drs. Janos KIrz and Harvey Rarback and the entire staff of the U15 beamline at the National Synchrotron Light Source who so generously gave their time and expert advice during the course of this work. We would also like to thank Mrs. Barbara Kponou for her skill in preparing the manuscript.

\section{REFEREHCES}

1. P. Fitz-James and E. Young: In The Bacterial Spore, ed. by G. Gould and A. Hurst, (Academic Press, NY, 1969) p. 39.

2. C. R. Phillips: Bact. Rev. 16, 135 (1952).

3. B. J. Panessa-Warren and J. B. Warren: Ann. NY Acad. Sc1. 342, 350 (1980).

4. J. Kirz and D. Sayre: In Synchrotron Radiation Research, ed. by S. Doniach and H. Winick, (Plenum Press, NY, 1980) p. 277.

5. J. Kirz: Ann. NY Acad. Sci. 342, 273 (1980).

6. L. Beese et al., Biophys. J. 49, 259 (1986).

\section{DISCLAIMER}

This report was prepared as an account of work sponsored by an agency of the United States Government. Neither the United States Government nor any agency thereof, nor any of their employees, makes any warranty, express or implied, or assumes any legal liability or responsibility for the accuracy, completeness, or usefulness of any information, apparatus, product, or process disclosed, or represents that its use would not infringe privately owned rights. Reference herein to any specific commercial product, process, or service by trade name, trademark, inanufactuser, of otherwise does not necessarily constitute or imply its endorsement, recommendation, or favoring by the United States Government or any agency thereor. The views and opinions of authors expressed herein do not necessarily state or reflect those of the United States Government or any agency thereof. 